\title{
Characteristics of the brackish water zone using a MEIS system in the Nakdong River Estuary (NRE), Busan City, South Korea
}

\author{
Jun-Ho LEE ${ }^{1 *}$, Han Jun Woo ${ }^{1}$, Hoi-Soo JUNG ${ }^{1}$
}

${ }^{1}$ Korean Seas Geosystem Research Unit, Korea Institute of Ocean Science and Technology, Busan, 49111, Republic of Korea (*correspondence: leejh@kiost.ac.kr)

\section{Marine Environmental Information (MEIS) System}

The Noksan Dam, built in 1934, blocks the flow of the West Nakdong River, and the Nakdong River Estuary (NRE) Dam (i.e. bank, dike, embankment, etc.) was completed between 1983 and 1987 to regulate the flow of the East Nakdong River [1]. Beginning in May 2015, the MEIS has been run in real time (1-s intervals) and has made periodic marine observations (one to four times a year). The real-time data consist of two items and the periodic marine observation data consist of five items [2].
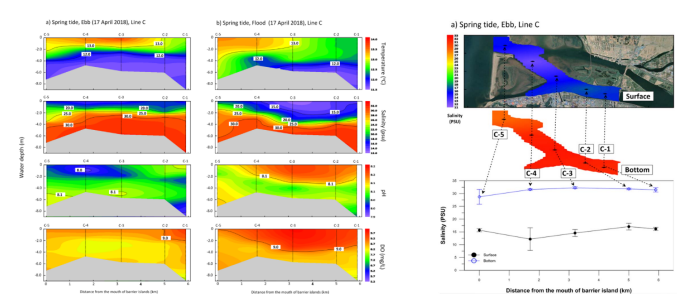

Figure 1: Horizontal-vertical distribution of salinity (psu) and etc. and stratification property during the spring tide (ebb and flood) in the Nakdong River Estuary (NRE), South Korea.

\section{Discussion of Results}

The average surface layer and lower layer salinities were 2.9-18.2 and 12.4-32.5 psu, respectively, and the mean surface-bottom layer difference in April and July was about $13.8 \mathrm{psu}$. In the stratification index (SI) analysis [3], the main stream of the Nakdong River showed a distinctive "salt wedge estuary" showing stratification during both the ebb and flood. In addition, the topographic characteristics of the moat form (east of the Eulsukdo mud flat and in front of the water line on the right side of Eulsukdo Island) were expected to represent large changes in the waterside geological and water quality after full or partial opening in 2021 to 2022.

[1] Williams et al. (2014) Mar. Geol. 357, 256-271. [2] Lee et al. (2019) J. Coastal Res. 91, 191-195. [3] Shaha et al. (2009) Hydrol. Earth Syst. Sci. 13, 923-933. 